\title{
TWO SLOW SURFACE WAVES ACROSS NORTH AMERICA*
}

\author{
By Frank Press and Maurice Ewing
}

\begin{abstract}
Surface shear waves $(\mathrm{Lg})$ with initial period about $1 / 2$ to $6 \mathrm{sec}$. with sharp commencements and amplitudes larger than any conventional phase have been recorded for continental paths at distances up to $6,000 \mathrm{~km}$. These waves have a group velocity of $3.51 \pm .07 \mathrm{~km} / \mathrm{sec}$. and for distances greater than $20^{\circ}$ they have reverse dispersion. For distances less than about $10^{\circ}$ the periods shorten and $\mathrm{Lg}$ merges into the recognized near-earthquake phase Sg.

An additional large amplitude phase in which the orbital motion of the particle is retrograde elliptical and the velocity is $3.05 \pm .07 \mathrm{~km} / \mathrm{sec}$. has also been observed for continental paths.

It is believed that these phases are propagated through a wave guide formed by a superficial sialic layer. The problem of explaining the propagation of these surface waves is that of finding a crustal structure which is consistent with the other data of geology and geophysics and which will provide a suitable wave guide for the new phases. A possible nature of the wave guide is described.
\end{abstract}

\section{INTRODUCTION}

LARGE surface waves with velocities between 3 and $3.5 \mathrm{~km} / \mathrm{sec}$. from shocks on the California coast were observed at Palisades shortly after the seismographs were installed. Shocks as small as magnitude 4.7 produced sharp phases giving consistent readings to within a few seconds at distances of about $35^{\circ}$. Some of the shocks arrived on an azimuth of almost due west, and as three components of motion were measured with seismographs having closely similar constants it was possible to identify two trains of waves, one exhibiting primarily SH motion, the other primarily Rayleigh type. Since the speeds were appropriate values for short-period Love and Rayleigh-type waves in a superficial sialic layer, the phases were called $\mathrm{Lg}$ and Rg. These phases were found on Palisades records for West Coast shocks from Mexico to Alaska, although the separation of the later phase Rg was not clear except for those coming from nearly west.

A few records from several other stations, including Pasadena, Berkeley, and St. Louis, and from shocks in several regions of North America were examined for Lg. The phase was followed in to epicentral distances of a few degrees, where it became identical with Sg. It was found for every continental path examined and for no mixed path with sizable ocean segment.

We shall attempt to show that Lg consists of SH waves multiply reflected within a superficial sialic layer.

The absence of the long-period branch Love waves and the duration of the wave traces cannot be accounted for on the theory of Love waves in any of the crustal structures usually assumed. The only explanation of these features which has occurred to the authors depends on the assumption of an "incompetent" layer in which the velocity of shear waves is very low.

Because of the conflict between this view and current concepts of continental structures, judgment on it is withheld until further investigations are completed.

* The research reported in this document has been made possible through support and sponsorship extended by the Geophysical Research Division of the Air Force Cambridge Research Center, under Contract AF19(122) 441. It is published for technical information only and does not represent recommendations or conclusions of the sponsoring agency.

Manuscript received for publication August 27, 1951. 

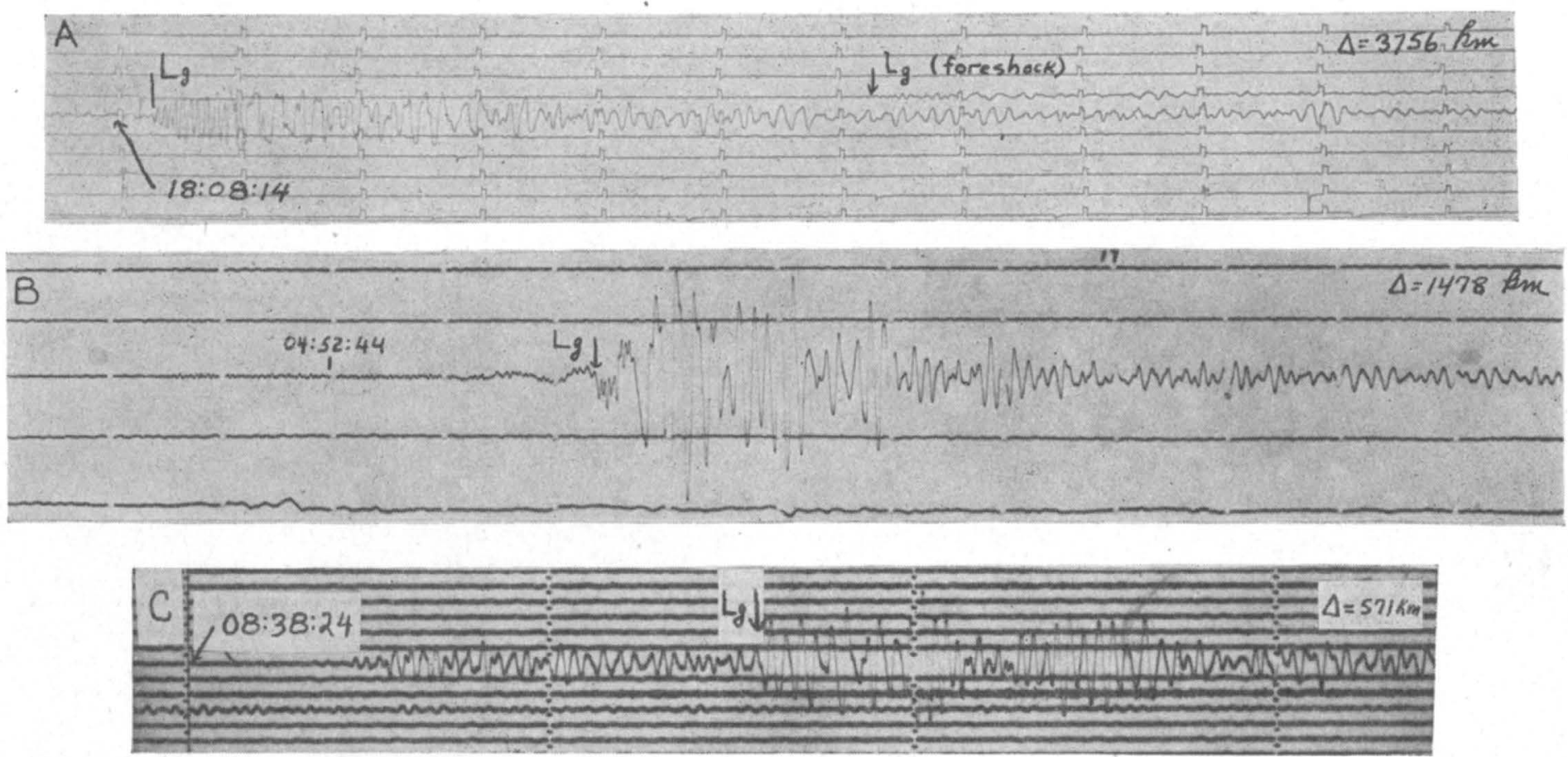

Fig. 1. Typical Lg phases: A, Palisades $N \rightarrow S$ seismogram tor shock $17 \mathrm{c} ; \mathrm{B}$, Pasadena linear strain seismogram for shock 9; C, Fresno $Z$ seismogram for shock $19 a$. 
The $L g$ phase.- Surface waves, for which we propose the symbol Lg, with initial period about $1 / 2$ to 6 sec. with sharp commencements and amplitudes far larger than those of any conventional phase have been recorded on continental paths at distances up to $6,000 \mathrm{~km}$. These waves have a group velocity of about $3.51 \pm .07$ $\mathrm{km} / \mathrm{sec}$, and for distances greater than about $20^{\circ}$ they have reverse dispersion (lower group velocities for longer periods). Typical appearance of the phase at about $4,000 \mathrm{~km}$. is as follows (see fig. 1): During the first few cycles the waves have approximately equal amplitudes on all three components, but the transverse horizontal rapidly gains amplitude and becomes several times larger than the other two within about 30 seconds. Approximately 1 minute after the commencement of the phase, the amplitude on the transverse component, having reached a value many times

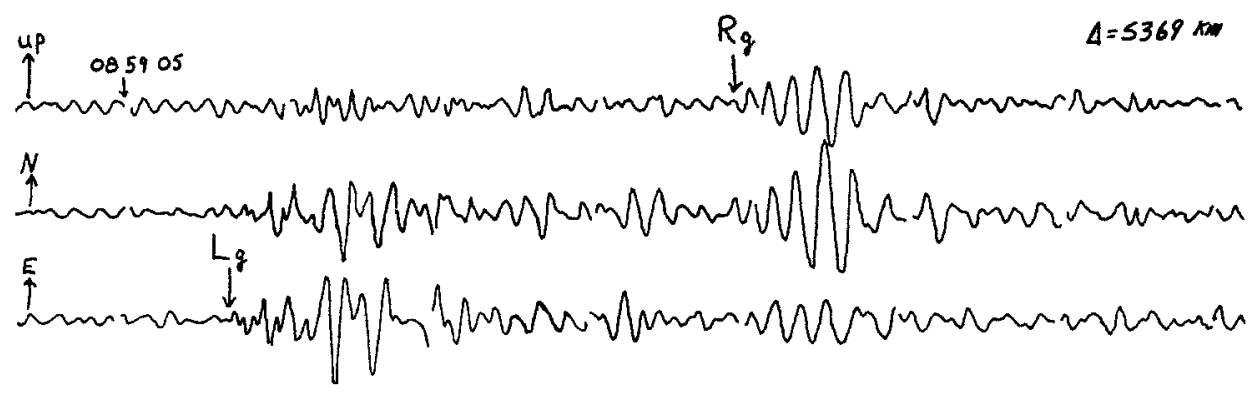

Fig. 2. Palisades seismograms illustrating $\mathrm{Lg}$ and Rg for shock $15 \mathrm{~b}$.

larger than that of S or SS on any component, begins to decrease gradually, but does not drop to a value comparable with that of SS until about 20 minutes later, the period then being of the order 10-14 sec. The group velocity for the latter part of this phase is certainly less than about $2 \mathrm{~km} / \mathrm{sec}$, the lower limit being uncertain.

For distances less than about $10^{\circ}$ the periods shorten and $\mathrm{Lg}$ merges into the recognized near-earthquake phase Sg.

The $R g$ phase.-The Rg phase also has large amplitudes on the seismogram. Its velocity is $3.05 \pm .07 \mathrm{~km} / \mathrm{sec}$, and the period of the maximum phase varies from 8 to 12 seconds. The orbital motion of a surface particle is retrograde elliptical. The dispersion is not marked, but when readable it is normal (i.e., the longer periods have higher group velocities). In the neighborhood of its largest amplitude it is easily distinguished from Lg on earthquakes whose azimuth from Palisades is due west by the complete absence of correlated large amplitudes on the north-south component. Its duration is difficult to determine because its amplitude decreases to approximately that of $\mathrm{Lg}$ only a few minutes after the maximum. Figure 2 shows typical $\mathrm{Rg}$ phase recorded at Palisades. At distances less than about $10^{\circ} \mathrm{Rg}$ merges into the recognized surface waves of near earthquakes.

\section{DATA}

The travel-time data for $\mathrm{Lg}$ and $\mathrm{Rg}$ are given in table 1 . Shocks with continental paths recorded at Palisades for which epicenter location and origin time are available form the basic material for this study. A few seismograms at Berkeley, Pasadena, and St. Louis have been examined during brief visits to these stations, and occa- 
TABLE I

\begin{tabular}{|c|c|c|c|c|c|c|c|c|c|c|c|c|}
\hline No. & Recording station & Date & & Hour & Latitude & Longitude & Magn. & $\Delta \mathrm{km}$. & \begin{tabular}{|c|} 
Lg Travel \\
Time. \\
sec.
\end{tabular} & $\begin{array}{c}\mathrm{Lg} \\
\text { Velocity, } \\
\text { km/sec. }\end{array}$ & $\begin{array}{c}\text { Rg Travel } \\
\text { Time, } \\
\text { sec. }\end{array}$ & $\begin{array}{l}\text { Rg } \\
\text { Velocity, } \\
\mathrm{km} / \mathrm{sec} .\end{array}$ \\
\hline 1 & Pasadena. & 18 Nov & 29 & 203158 & $44^{\circ} \mathrm{N}$ & $56^{\circ} \mathrm{W}$ & 7.2 & 5344 & 1443 & 3.70 & & \\
\hline $2 \mathrm{a}$ & Pasadena. & $16 \mathrm{Aug}$ & 31 & 114021 & $30^{\circ} 53^{\prime} \mathrm{N}$ & $104^{\circ} 11^{\prime} \mathrm{W}$ & 6.4 & 1358 & 387 & 3.51 & & \\
\hline $2 \mathrm{~b}$ & Tacubaya. & 16 Aug & 31 & 114021 & $30^{\circ} 53^{\prime} \mathrm{N}$ & $104^{\circ} 11^{\prime} \mathrm{W}$ & 6.4 & 1367 & 397 & 3.44 & & \\
\hline $2 \mathrm{c}$ & Ottawa... & $16 \mathrm{Aug}$ & 31 & 114021 & $30^{\circ} 53^{\prime} \mathrm{N}$ & $104^{\circ} 11^{\prime} \mathrm{W}$ & 6.4 & 2944 & 837 & 3.52 & & \\
\hline 3 & Charlottesville. & 16 Aug & 31 & 114021 & $30^{\circ} 53^{\prime} \mathrm{N}$ & $104^{\circ} 11^{\prime} \mathrm{W}$ & 6.4 & 2478 & 725 & 3.42 & & \\
\hline 4 & Pasadena. & 10 July & 33 & 032204 & $19^{\circ} \mathrm{N}$ & $1031 / 2^{\circ} \mathrm{W}$ & $61 / 4$ & 2222 & 667 & 3.33 & & \\
\hline 5 & Pasadena. & 20 Nov & 33 & 232138 & $73.3 \mathrm{~N}$ & $70: 7 \mathrm{~W}$ & 7.3 & 5077 & 1448 & 3.51 & & \\
\hline 6 & Pasadena. & $19 \mathrm{Dec}$ & 33 & 174830 & $74: 0 \mathrm{~N}$ & $70: 0 \mathrm{~W}$ & & 5136 & 1459 & 3.52 & & \\
\hline 7 & Pasadena. & $12 \mathrm{Mar}$ & 34 & 182018 & $41: 8 \mathrm{~N}$ & $113: 0 \mathrm{~W}$ & & 962 & 271 & 3.55 & & \\
\hline 8 & Pasadena. & 31 Aug & 34 & 050252 & $73: 3 \mathrm{~N}$ & $70: 7 \mathrm{~W}$ & $61 / 2$ & 5077 & 1442 & 3.52 & & \\
\hline 9 & Pasadena. & 19 Oet & 35 & 044803 & $46^{\circ} 6 \mathrm{~N}$ & $112^{\circ} \mathrm{W}$ & $61 / 4$ & 1478 & 424 & 3.49 & & \\
\hline 10 & Pasadena. & 31 Oet & 35 & 183749 & $46.5 \mathrm{~N}$ & $112^{\circ} \mathrm{W}$ & 6 & 1468 & 420 & 3.50 & & \\
\hline 11 & Pasadena. & 1 Nov & 35 & 060340 & $46: 8 \mathrm{~N}$ & $79.2 \mathrm{~W}$ & & 3536 & 1021 & 3.46 & & \\
\hline 12 & St. Louis. & 13 Nov & 49 & 195539 & $47: 1 \mathrm{~N}$ & $122.7 \mathrm{~W}$ & & 2783 & 791 & 3.52 & & \\
\hline 13 & Palisades. & 1 Jan & 50 & 025121 & $26^{\circ} \mathrm{N}$ & $110^{\circ} \mathrm{W}$ & & 3700 & 1097 & 3.37 & & \\
\hline 14 & Palisades. & $16 \mathrm{Apr}$ & 50 & 214802 & $49^{\circ} \mathrm{N}$ & $129^{\circ} \mathrm{W}$ & & 4318 & 1171 & 3.69 & 1391 & 3.10 \\
\hline $15 \mathrm{a}$ & St. Louis. & 25 May & 50 & 083432 & $651 / 2^{\circ} \mathrm{N}$ & $1511 / 2^{\circ} \mathrm{W}$ & 6 & 4847 & 1391 & 3.48 & & \\
\hline $15 \mathrm{~b}$ & Palisades. & 25 May & 50 & 083432 & $6512^{\circ} \mathrm{N}$ & $1511 / 2^{\circ} \mathrm{W}$ & 6 & 5369 & 1517 & 3.54 & 1703 & 3.15 \\
\hline 16 & Palisades. & 5 July & 50 & 183008 & $62^{\circ} \mathrm{N}$ & $155^{\circ} \mathrm{W}$ & & 5626 & 1538 & 3.66 & 1781 & 3.16 \\
\hline $17 \mathrm{a}$ & Florissant. . & $28 \mathrm{July}$ & 50 & 175046 & $33^{\circ} \mathrm{N}$ & $1151 / 2^{\circ} \mathrm{W}$ & 5.3 & 2343 & 665 & 3.52 & 790 & 2.97 \\
\hline $17 \mathrm{~b}$ & St. Louis... & 28 July & 50 & 175046 & $33^{\circ} \mathrm{N}$ & $1151 / 2^{\circ} \mathrm{W}$ & 5.3 & 2352 & 651 & 3.61 & & \\
\hline $17 \mathrm{c}$ & Palisades. & 28 July & 50 & 175046 & $33^{\circ} \mathrm{N}$ & $1151 / 2^{\circ} \mathrm{W}$ & 5.3 & 3756 & 1064 & 3.53 & & \\
\hline $18 \mathrm{a}$ & Florissant. & 29 July & 50 & 143633 & $33^{\circ} \mathrm{N}$ & $1151 / 2^{\circ} \mathrm{W}$ & 5.4 & 2343 & 663 & 3.53 & 783 & 2.99 \\
\hline $18 \mathrm{~b}$ & St. Louis. & 29 July & 50 & 143633 & $33^{\circ} \mathrm{N}$ & $1151^{1} 2^{\circ} \mathrm{W}$ & 5.4 & 2352 & 661 & 3.56 & & \\
\hline $18 \mathrm{c}$ & Palisades. & 29 July & 50 & 143633 & $33^{\circ} \mathrm{N}$ & $1151 / 2^{\circ} \mathrm{W}$ & 5.4 & 3756 & 1061 & 3.54 & 1247 & 3.01 \\
\hline $19 \mathrm{a}$ & Fresno... & $1 \mathrm{Aug}$ & 50 & 083718 & $33^{\circ} \mathrm{N}$ & $11512^{\circ} \mathrm{W}$ & 4.7 & 571 & 160 & 3.57 & & \\
\hline $19 \mathrm{~b}$ & Reno.... & 1 Aug & 50 & 083718 & $33^{\circ} \mathrm{N}$ & $11512^{\circ} \mathrm{W}$ & 4.7 & 822 & 245 & 3.36 & & \\
\hline $19 \mathrm{c}$ & Palisades. & 1 Aug & 50 & 083718 & $33^{\circ} \mathrm{N}$ & $1151 / 2^{\circ} \mathrm{W}$ & 4.7 & 3756 & 1064 & 3.53 & 1184 & 3.17 \\
\hline 20 & Palisades. & 8 Aug & 50 & 051200 & $55^{\circ} \mathrm{N}$ & $1341 / 2^{\circ} \mathrm{W}$ & & 4600 & 1283 & 3.59 & 1482 & 3.10 \\
\hline
\end{tabular}




\begin{tabular}{|c|c|c|c|c|c|c|c|c|c|c|c|c|}
\hline $21 \mathrm{a}$ & St. Louis. . . . . . . . . . & 24 Aug & 50 & 174534 & $421 / 2^{\circ} \mathrm{N}$ & $126^{\circ} \mathrm{W}$ & & 3026 & 899 & 3.37 & & \\
\hline $21 b$ & Palisades . . . . . . . . . & 24 Aug & 50 & 174534 & $421 / 2{ }^{\circ} \mathrm{N}$ & $126^{\circ} \mathrm{W}$ & & 4251 & 1204 & 3.53 & 1419 & 3.00 \\
\hline 22 & Palisades. . . . . . . . . & 25 Aug & 50 & 021510 & $491 / 2^{\circ} \mathrm{N}$ & $129^{\circ} \mathrm{W}$ & $\cdot$ & 4310 & 1258 & 3.43 & 1418 & 3.04 \\
\hline 23 & Palisades. & $26 \mathrm{Aug}$ & 50 & 043927 & $65^{\circ} \mathrm{N}$ & $162^{\circ} \mathrm{W}$ & $61 / 2$ & 5859 & 1670 & 3.51 & 1859 & 3.15 \\
\hline 24 & Palisades. & 24 Sept & 50 & 221328 & $64^{\circ} \mathrm{N}$ & $156^{\circ} \mathrm{W}$ & & 5617 & 1646 & 3.41 & & \\
\hline 25 & Palisades. & 28 Sept & 50 & 214701 & $541 / 2^{\circ} \mathrm{N}$ & $1341 / 2^{\circ} \mathrm{W}$ & & 4607 & 1299 & 3,55 & & \\
\hline 26 & Palisades. . . . . . . . & 3 Oet & 50 & 090403 & $66^{\circ} \mathrm{N}$ & $161^{\circ} \mathrm{W}$ & & 5777 & 1671 & 3.46 & & \\
\hline 27 & Palisades. . & 3 Oct. & 50 & 124008 & $651 / 2{ }^{\circ} \mathrm{N}$ & $128^{\circ} \mathrm{W}$ & & 4292 & 1201 & 3.57 & 1353 & 3.17 \\
\hline 28 & Tucson............. & 23 Oct & 50 & 161324 & $14 /^{\circ} \mathrm{N}$ & $92^{\circ} \mathrm{W}$ & 7.2 & 2744 & 795 & 3,45 & & \\
\hline 29 & St. Louis............ & 11 Nov & 50 & 092823 & $191 / 2{ }^{\circ} \mathrm{N}$ & $110^{\circ} \mathrm{W}$ & & 2850 & 802 & 3.55 & & \\
\hline 30 & Tucson............. & 17 Nov & 50 & 192818 & $17^{\circ} \mathrm{N}$ & $1001 / 2^{\circ} \mathrm{W}$ & $63 / 4-7$ & 1989 & 559 & 3.56 & & \\
\hline $31 a$ & Florissant.......... & 14. Dec & 50 & 132421 & $40.1 \mathrm{~N}$ & $120^{\circ} .2 \mathrm{~W}$ & & 2551 & 714 & 3.57 & & \\
\hline $31 b$ & St. Louis.. & 14 Dec & 50 & 132421 & $40^{\circ} .1 \mathrm{~N}$ & $120.2 \mathrm{~W}$ & & 2566 & 738 & 3.48 & & \\
\hline $31 \mathrm{c}$ & Palisades........... & $14 \mathrm{Dec}$ & 50 & 132421 & $40^{\circ} 1 \mathrm{~N}$ & $120^{\circ} .2 \mathrm{~W}$ & & 3861 & 1081 & 3.57 & 1269 & 3.04 \\
\hline 32 & Palisades........... & $16 \mathrm{Dec}$ & 50 & 104901 & $431 / 2^{\circ} \mathrm{N}$ & $127^{\circ} \mathrm{W}$ & & 4300 & 1293 & 3.33 & 1439 & 2.99 \\
\hline $33 a$ & St. Louis. . & $3 \mathrm{Jan}$ & 51 & 122131 & $18^{\circ} \mathrm{N}$ & $106^{\circ} \mathrm{W}$ & $61 / 4$ & 2754 & 815 & 3.38 & & \\
\hline $33 \mathrm{~b}$ & Palisades......... & $3 \mathrm{Jan}$ & 51 & 122131 & $18^{\circ} \mathrm{N}$ & $106^{\circ} \mathrm{W}$ & $61 / 4$ & 3980 & 1193 & 3.34 & 1320 & 3.02 \\
\hline $34 a$ & St. Louis............. & $3 \mathrm{Jan}$ & 51 & 130424 & $18^{\circ} \mathrm{N}$ & $106^{\circ} \mathrm{W}$ & & 2754 & 826 & 3.33 & & \\
\hline $34 \mathrm{~b}$ & Palisades. & $3 \mathrm{Jan}$ & 51 & 130424 & $18^{\circ} \mathrm{N}$ & $106^{\circ} \mathrm{W}$ & $61 / 4$ & 3980 & 1202 & 3.31 & 1367 & 2.91 \\
\hline $35 \mathrm{a}$ & Berkeley. . . . . . . . & $24 \mathrm{Jan}$ & 51 & 071701 & $33^{\circ} \mathrm{N}$ & $115^{3} / 4^{\circ} \mathrm{W}$ & $53 / 4$ & 800 & 218 & 3.67 & & \\
\hline $35 \mathrm{~b}$ & Palisades. & 24 Jan & 51 & 071701 & $33^{\circ} \mathrm{N}$ & $115^{3} / 4^{\circ} \mathrm{W}$ & $5 \% / 4$ & 3777 & 1069 & 3.53 & 1238 & 3.05 \\
\hline $36 a$ & Tucson............. & $30 \mathrm{Jan}$ & 51 & 190030 & $151 / 2^{\circ} \mathrm{N}$ & $99^{\circ} \mathrm{W}$ & $61 / 4-61 / 2$ & 2212 & 620 & 3.57 & & \\
\hline $36 b$ & Tucson $\ldots \ldots \ldots \ldots$ & $30 \mathrm{Jan}$ & 51 & 190030 & $151 / 2^{\circ} \mathrm{N}$ & $99^{\circ} \mathrm{W}$ & $61 / 4-61 / 2$ & 2212 & 602 & 3.67 & & $*$ \\
\hline 37 & Palisades. . & 1 April & 51 & 192110 & $401 / 2^{\circ} \mathrm{N}$ & $125^{\circ} \mathrm{W}$ & & 4236 & 1207 & 3.51 & & \\
\hline 38 & Palisades............ & 22 April & 51 & 123616 & $76^{\circ} \mathrm{N}$ & $73^{\circ} \mathrm{W}$ & & 3889 & 1088 & 3.57 & 1289 & 3.02 \\
\hline $39 a$ & Ottawa. & 20 June & 51 & 183710 & $351 / 2^{\circ} \mathrm{N}$ & $103^{\circ} \mathrm{W}$ & & 2544 & 718 & 3.54 & & \\
\hline $39 \mathrm{~b}$ & Palisades....... . & 20 June & 51 & 183710 & $351 / 2^{\circ} \mathrm{N}$ & $103^{\circ} \mathrm{W}$ & & 2598 & 736 & 3.53 & & \\
\hline 40 & Palisades.......... & 23 June & 51 & 033240 & $311 / 2^{\circ} \mathrm{N}$ & $1131 / 2^{\circ} \mathrm{W}$ & & 3663 & 1080 & 3.39 & 1222 & 3.00 \\
\hline 41 & Palisades.......... & 25 June & 51 & 161232 & $61^{\circ} \mathrm{N}$ & $150^{\circ} \mathrm{W}$ & $6 \frac{1}{4}$ & 5395 & 1513 & 3.57 & & * \\
\hline
\end{tabular}

* Focal depth $100 \mathrm{~km}$. 
sional readings from other stations have been used primarily to demonstrate that the Palisades results are typical. Figure 3 shows the paths of Lg for these earthquakes.

Although the instrumentation at Palisades has increased considerably beyond that available for our earlier recordings, the first instruments installed here were quite good for this study. They provided three well-matched components with good re-

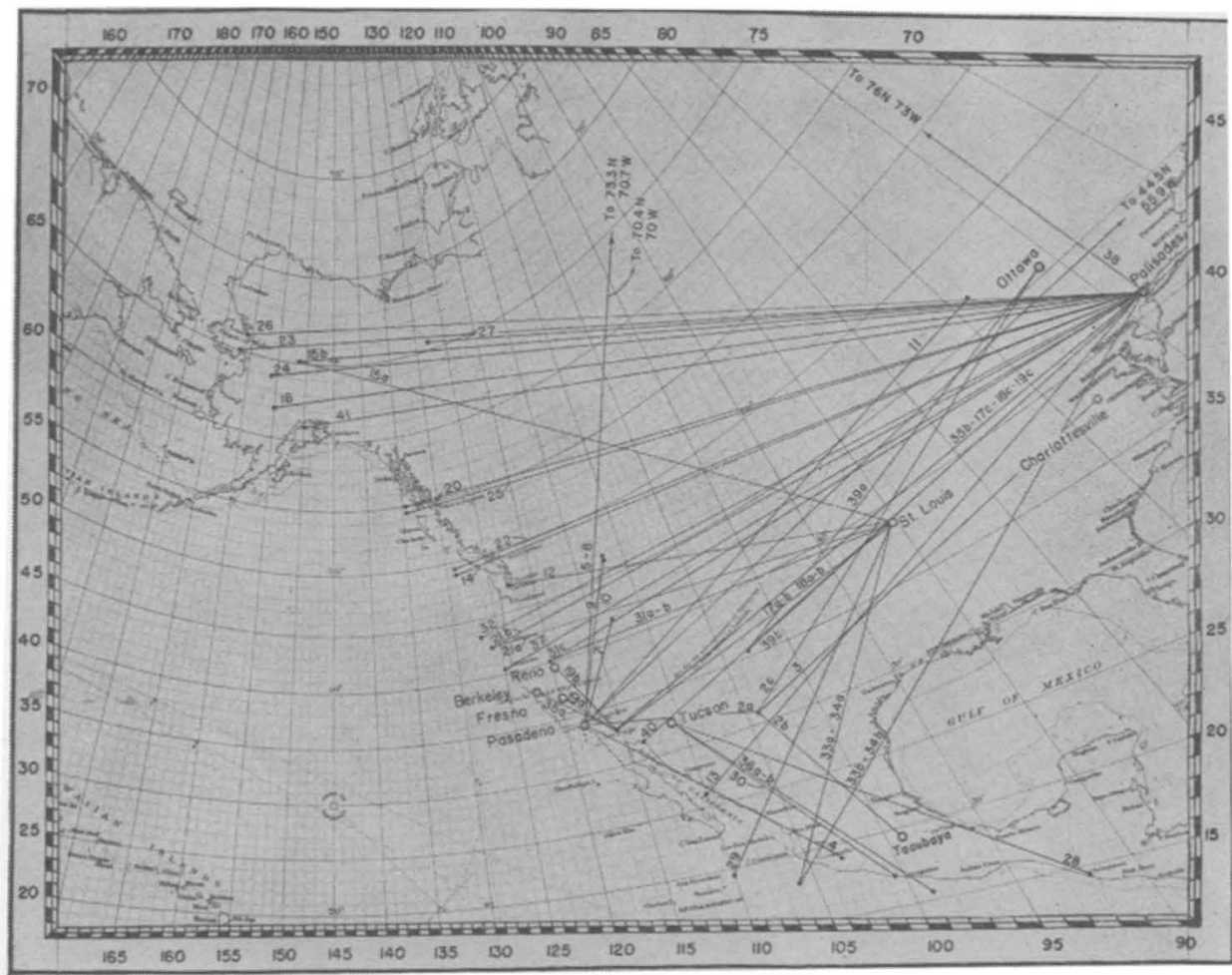

Fig. 3. Paths traversed by $\operatorname{Lg}$ phases listed in table 1.

sponse in the period range of $\mathrm{Lg}$ and $\mathrm{Rg}$. It is difficult to identify $\mathrm{Rg}$ without a vertical which matches the horizontals, and even with such instrumentation it was a great advantage to learning the distinctive features of these phases that many of the shocks arrived from due west.

The readings at Pasadena were made from an excellent file of records selected several years ago by Gutenberg and Richter. This file was arranged in the order of increasing epicentral distances, and there were but few gaps of more than 1 or 2 degrees epicentral distance. Every record in this file was examined, regardless of the nature of the path. It was found that $\mathrm{Lg}$ was recorded only for continental paths.

It is apparent from the velocity and large amplitudes that $\mathrm{Lg}$ is a wave which is confined to a surface or near-surface layer by wave-guide action. Regardless of the details of the wave guide, no energy will be radiated into the region below the Mohorovičic discontinuity from any wave whose phase velocity is less than about $4.7 \mathrm{~km} / \mathrm{sec}$, the velocity of shear waves below this discontinuity. The problem of 
explaining the propagation of the surface waves reported in this paper is that of finding a crustal structure which is consistent with the other data of geology and geophysics, and which will provide a wave guide for the new phases introduced here which require group velocities of about $3.5 \mathrm{~km} / \mathrm{sec}$. at periods of about 2 seconds and less than $2 \mathrm{~km} / \mathrm{sec}$. at periods of about 12 seconds.

\section{Possible Nature of Wave Guide}

In the first attempt to explain this surface wave, the authors were impressed with the similarity of its commencement with that of the compressional wave in shallowwater transmission ${ }^{1}$ (fig. 4). $\mathrm{Lg}$ was therefore considered to be the high-frequency branch of the classical Love-wave dispersion curve in a sialic surface layer, but this

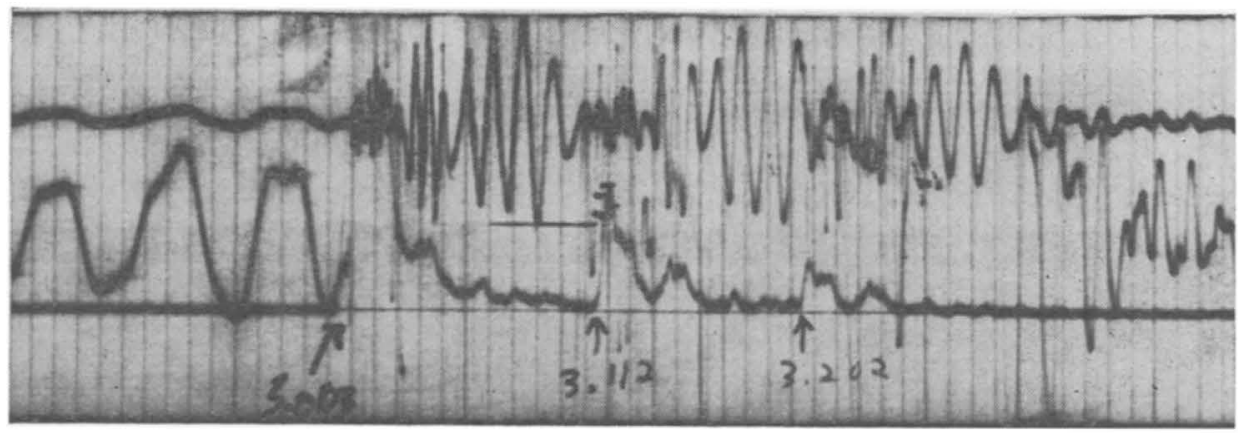

Fig. 4. Typical seismogram from a shallow-water shot, illustrating reverse dispersion in the water wave.

hypothesis was quickly abandoned for the reasons (1) that no trace of the longperiod branch of Love waves could be found and (2) that the duration of the wave train, which depends upon the ratio between the short-period group velocity and the minimum of group velocity, is an order of magnitude larger than allowed by Love-wave theory; (3) the motion on the other two components required some extension of the classical Love-wave theory.

Alternative hypothesis allowing group velocities low enough to explain the duration of the transverse motion must involve multiple reflection of SH waves in a solid surface layer at angles of incidence approaching normal. One example of this type of propagation is that of Love waves if the theory be extended to include transmissions at angles steeper than the critical angle with attendant leakage of energy into the substratum. This type of transmission has been observed for the analagous case of multiple reflected compressional waves in shallow water underlain by a smooth rock bottom, the loss of energy through leakage being compensated by automatic volume control of the recording system. ${ }^{2}$ Use of multiple detectors-the usual geophysical reflection spread-showed that the phase velocity approached infinity as the group velocity approached zero. Despite the unusually large contrast in acoustical impedance at the sea floor in this case, simple amplitude calculations

${ }^{1}$ Maurice Ewing, J. L. Worzel, C. L. Pekeris, "Propogation of Sound in The Oceans" (Geol. Soc. Am., Memoir No. 27; 1948).

2 K. E. Burg, Maurice Ewring, Frank Press, and E. J. Stulken, "A Seismic Wave Guide Phenomenon," Geophysics, 16:594-612 (1951). 
indicate that without the large time increase of amplitude gain provided by use of automatic volume control this type of propagation would not have been observable.

Similar amplitude considerations in the case of the Lg phase, as well as the complete absence of a longer-period branch of Love waves, seems to rule out the possibility that the layer through which $\mathrm{Lg}$ is propagated is underlain by a solid having a value of shear velocity anywhere near that of the layer.

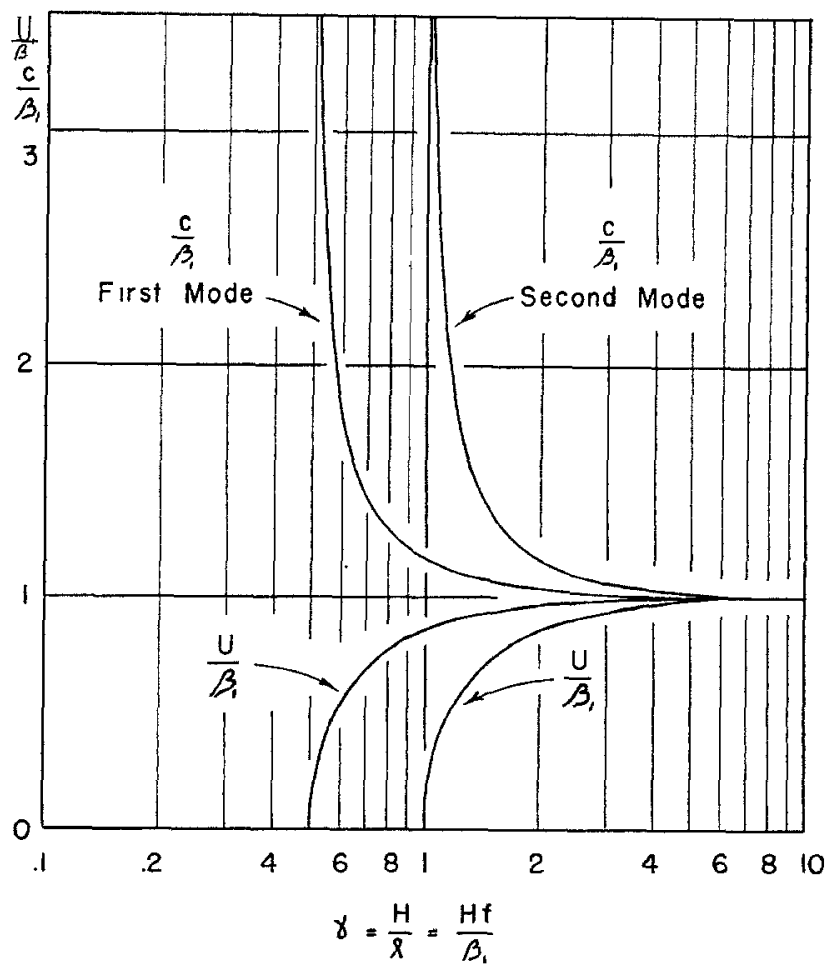

Fig. 5. Dimensionless phase velocity $c / \beta_{1}$ and group velocity $U / \beta_{1}$ curves for $\mathrm{SH}$ waves in a plate.

A second example is the propagation of $\mathrm{SH}$ waves in a plate, by means of multiple internal reflections. Typical dispersion for this case is shown in figure 5, taken from a paper by Press and Ewing. ${ }^{3}$ According to this dispersion curve, the first oscillations at a point whose distance from an impulsive source is large as compared to the plate thickness, travel with the velocity $\beta$, of shear waves in the plate, and have high frequencies and an impulsive beginning. The train of waves which follows is of infinite duration and decreases in frequency to a cut-off value of $f=n \beta / 2 H$, where $H$ is the thickness of the plate and $n=1,2,3 \ldots$ is the mode of propagation. The $\mathrm{SH}$ waves in a plate which is in contact with a fluid substratum cannot "leak" out of the plate, even for angles of incidence approaching normal. In a general way an earth model in which a sialic plate rests on a "fluid" substratum could explain the main features of the $\mathrm{Lg}$ waves as observed on a transverse horizontal seismograph.

${ }^{3}$ Frank Press and Maurice Ewing, "Propagation of Elastic Waves in a Floating Ice Sheet," Trans. Am. Geophys. Union, 32:673-678 (1951). 
The theory for propagation of SV waves in a plate floating on a fluid substratum of finite thickness is more complicated, owing to the transformation of part of the energy into compressional waves at each reflection, but its general features can be deduced from the work on the floating ice sheet, in which the thickness of the fluid substratum was unlimited. According to this theory there is an infinite number of modes of propagation. In the first mode a short-period Rayleigh wave at speed $0.92 \beta$ is predicted at one end of the spectrum, with a longitudinal wave with velocity appropriate to the plate at the long-period end. There is wave-guide propagation with no leakage for the short-period Rayleigh waves, but the long-period longitudinal waves will suffer attenuation through radiation of energy into the fluid. In higher modes it can be shown that the first arrival of short-period SV waves is simultaneous with the $\mathrm{SH}$ waves which initiate $\mathrm{Lg}$ in the foregoing discussion.

Furthermore, the impulsive, high-frequency beginning of SV waves propagated in the second mode is similar to that for SH waves, corresponding to the disturbances in the other two components as described above. If both modes are present, the first motion due to SV would be high-frequency waves at the velocity $\beta$ on the vertical and longitudinal components showing reverse dispersion. They would be followed, at a velocity $0.92 \beta$, by Rayleigh waves whose period corresponds to a wave length which is small as compared to the thickness of the plate. The subsequent part of the record would consist of a mixture of the two modes, but in the case of the hypothetical earth structure added features would be introduced by the finite thickness of the liquid layer and by propagation through the underlying solid which controls the propagation of the long-period Rayleigh waves.

According to this theory we might expect long longitudinal waves commencing with a velocity $0.94 \alpha$ and compressional waves of short period commencing with the velocity $\alpha$, but these will be much more strongly attenuated than the Lg waves, owing to greater leakage of energy through the liquid layer. Clearly, the effect of viscosity also must be considered.

The numerous curious features of $\mathbf{S}$ are well known. A partial list includes poor transmission from shallow shocks for distances between $5^{\circ}$ and $25^{\circ}$, periods markedly different from that of $\mathrm{P}$, and dependence of travel time on polarization. It is clear that a thin, viscous, semiliquid layer at or above the base of the crust would strongly affect shear waves, particularly in the shorter-period range. Such a layer could not readily be detected by travel-time techniques, excluding those where the focal depth varies to exceed layer depth. It is mostly by surface-wave studies, reflections, and amplitude studies such as used by Gutenberg ${ }^{4}$ that this layer could be detected. We believe that the evidence which led Gutenberg to propose the existence of a lowvelocity layer is not inconsistent with the existence of a semiliquid layer near the base of the crust.

\section{Conclusions}

The fact that Lg is observed for continental paths only, being gradually eliminated as the ocean path increases beyond $100 \mathrm{~km}$., offers good support to the conclusion, based on Rayleigh-wave propagation across oceans $s^{5}$ and on seismic-refraction inves-

\footnotetext{
4 B. Gutenberg, "Structure of the Earth's Crust in the Continents," Science, 111:29-30 (1950).

"Maurice Ewing and Frank Press, "Crustal Structure and Surface Wave Dispersion," Bull. Seism. Soc. Am., 40:271-280 (1950).
} 
tigations of ocean basins, ${ }^{6}$ that the sialic layer is limited to continents only. There are many observatories so located that the occurrence of $\mathrm{Lg}$ on a record would be highly diagnostic for immediate epicenter location. $\mathrm{Lg}$ is a powerful tool for the investigation of crustal structure under small bodies of water, provided paths are chosen so that lateral refraction does not introduce complications. For example, the possibility that sialic crust of continental thickness underlies the Gulf of Mexico may be quickly rejected by inspection of the Palisades records from shocks off Mexico.

The high quality of the wave guide which transmits $\mathrm{Lg}$ is remarkable. The efficient energy transmission from small earthquakes and the similarity of various North American paths except those along mountain systems means that a simple set of parameters will specify the "mean" sialic crust. This suggests that on the whole the sialic crust of the continent approximates a plate with good precision. We interpret this broadly: roots of mountain systems and other thickness variations of limited lateral extent would not prevent transmission of $\mathrm{Lg}$, although they would affect the regularity of the dispersion. On the other hand, propagation along the mountain systems of the west coast of North America alters the velocity and character of Lg.

The apparent discrepancy between the uniform, homogeneous continental crust revealed by $\mathrm{Lg}$ and the highly irregular one revealed by seismic-refraction measurements using explosions as sources, is probably explained completely by the difference in the wave lengths used in the two techniques.

6 Maurice Ewing, J. L. Worzel, J. B. Hersey, Frank Press, and G. R. Hamilton, "Refraction Measurements in the Atlantic Ocean Basin, Part I," Bull. Seism. Soc. Am., 40:233-242 (1950).

Lamont Geological Observatory

(Columbia UnIVersity)

Contribution No. 61. 